\title{
Factors related to methamphetamine relapse risk among clients in the substance rehabilitation center of National Narcotics Board in West Java, Indonesia
}

Methamphetamine relapse risk

Gian Nurmaindah Hendianti and Penpaktr Uthis Faculty of Nursing, Chulalongkorn University, Bangkok, Thailand

\begin{abstract}
Purpose - This purpose of this paper is to describe methamphetamine relapse risk, examine the relationship between factors in the dynamic model of relapse and methamphetamine relapse risk.

Design/methodology/approach - A total of 165 clients from the Substance Rehabilitation Center of National Narcotics Board in West Java, Indonesia were recruited. The research instruments included a demographic characteristic questionnaire and eight different tests: Drug Taking Confidence Questionnaire; Stimulant Effect Expectancy Questionnaire; Stage of Change Readiness and Treatment Eagerness Scale version 8.0 for Drug; Coping Strategies Inventory Short Form; Positive Affect and Negative Affect Schedule; Desire for Speed Questionnaire; Social Support Questionnaire; and the Stimulant Relapse Risk Scale. Descriptive statistics were used to analyze the data. Pearson's product moment correlation was used to test the relationship among variables. Findings - Clients (63 percent) were at a moderate level of methamphetamine relapse risk (mean $=56.33$, $\mathrm{SD}=10.54$ ). Outcome expectancy, positive emotional state, negative emotional state and craving were positive and had a significant correlation with relapse risk $(r=0.261, r=0.380, r=0.370, r=0.509, p<0.01$, respectively). Self-efficacy was negative and had a significant correlation with relapse risk $(r=-0.316$, $p<0.01)$. Motivation, coping and social support had no correlation with relapse risk.

Originality/value - Two-thirds of the clients in a rehabilitation center have a tendency to relapse following treatment. Nursing intervention for early detection of methamphetamine relapse risk during treatment by using standardized instruments should be implemented.
\end{abstract}

Keywords Rehabilitation, Methamphetamine, Relapse risk, Dynamic model of relapse

Paper type Research paper

\section{Introduction}

The National Narcotics Board (NNB) in Indonesia Situation Assessment on ATS figured the numbers of drug users in 2011 was around $4.7 \mathrm{~m}$ people; and $1.3 \mathrm{~m}$ of those users abused crystalline methamphetamine[1]. The number of drug users in Indonesia has shown insignificant reduction within from 2007 to 2011[2]. Methamphetamine belongs to a group of synthetic stimulants that are potently addictive and cause withdrawal symptoms during cessation[3]. There are three phases of substance abuse treatment under the Indonesian

(C) Gian Nurmaindah Hendianti and Penpaktr Uthis. Published in the Journal of Health Research. Published by Emerald Publishing Limited. This article is published under the Creative Commons Attribution (CC BY 4.0) licence. Anyone may reproduce, distribute, translate and create derivative works of this article (for both commercial and non-commercial purposes), subject to full attribution to the original publication and authors. The full terms of this licence may be seen at http://creativecommons. org/licences/by/4.0/legalcode

This study was approved by the Institutional Review Board from the Ethical Committee of Health Research Medical Faculty of Padjadjaran University (Approval Letter No. 889/UN6.C.10/PN/2017). This study is supported by Graduate School Thesis Grant, Chulalongkorn University.

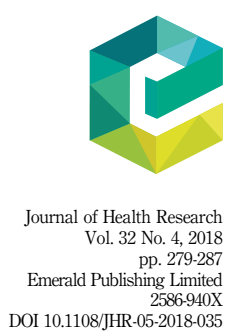

Received 15 November 2017 Accepted 10 April 2018

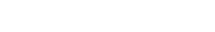


JHR

32,4

280

$\mathrm{NNB}$, including detoxification phase, primary or rehabilitation phase and aftercare phase[4]. There are seven separated wards of the rehabilitation phase. These are: the entry unit to prepare clients before entering the rehabilitation phase, house of faith and house of hope for long-term rehabilitation (six months), house of care and house of change for short term rehabilitation (four month), house of females and re-entry unit to prepare clients prior to the aftercare phase. Currently, there is no study on drug relapse, specifically on methamphetamine users in Indonesia; however, there are some studies in Asia that support the high rate of relapse in the methamphetamine user population. Notably, the relapse rate of methamphetamine users in Cambodia, Laos and Thailand was extremely high, amounting to almost 100 percent of post-treatment cases[5].

Methamphetamine relapse is a resumption of methamphetamine after at least six months of voluntary abstinence and/or resumption of methamphetamine after discharge from a mandated treatment program[6]. It can be concluded that relapse commonly occurs post-treatment. Currently, researchers have been interested in preventing this problem. As such, a concept of "relapse risk" has been invented in the last decade. Ogai et al. defined relapse risk as a clinical sign and symptoms which precede relapse during post-treatment[7].

The term relapse risk is also mentioned in the Relapse Prevention Model (RPM) of Marlatt and Gordon in 1985[8]. It contains several factors that contribute to relapse including selfefficacy, outcome expectancy, motivation, coping, emotional state, craving and social support. It was then developed to a Dynamic Model of Relapse by Witkiewitz and Marlatt in 2004, and that contains similar factors to the RPM, with the addition of physical withdrawal $[9,10]$. The difference is the Dynamic Model of Relapse views relapse as a nonlinear process in which various factors act jointly to affect relapse timing and severity[10]. The population of this study was taken from clients in a rehabilitation treatment setting, having already passed the detoxification phase and also not showing any physical withdrawal. Therefore, physical withdrawal was excluded from the selected independent variable of the study.

Evidence from past studies highlighted the relationship between the factors of RPM components with relapse and relapse risk for stimulant drug users. Higher levels of self-efficacy are associated with prolonged abstinence and a lower risk of relapse[11, 12]. The effect of drugs and the expected outcomes correlated with the use of the drug creates desire; in which, it can increase the prevalence of relapse risk $[8,13]$. Being motivated to abstain influences self-efficacy and outcomes which decreases relapse risk[14, 15]. The coping strategies that a client employs with stressful life events is associated with the risk of relapse and the periods of abstinence[16, 17]. Negative emotional state increases the risk of relapse while positive emotional state decreases $\mathrm{it}[16,18]$. Craving precedes methamphetamine relapse in the first week immediately following abstinence from the treatment[19, 20]. At last, presence of a support system of people and the quality of social support are related to the relapse risk and number of abstinence days after treatment[21-23].

\section{Methods}

This descriptive correlation study was conducted at six wards of rehabilitation phase treatment in the Substance Rehabilitation Center of NNB in West Java among adults who were diagnosed with methamphetamine use disorder. A dependent variable of this study is methamphetamine relapse risk; and the independent variables of this study are self-efficacy, outcome expectancies, motivation, coping including engagement and disengagement coping, emotional state including positive and negative emotional state, craving and social support. In total, this study has ten variables. Based on Thorndike's method, 150 subjects were required as a sample. In order to overcome the missing data, 165 subjects were recruited. A purposive sampling technique was used to recruit the subjects. The inclusion criteria were: male and female adults aged 20-65 years old who met the criteria for 
methamphetamine use disorder based on stimulant-related disorder criteria in DSM-5, no cognitive impairment as shown by Mini-Mental State Examination score, no limitation of communication, and willing to participate in the study. Finally, 17 subjects were recruited from the entry unit; 31 subjects were recruited from the re-entry unit; 30 subjects were recruited from the house of faith; 37 subjects were recruited from the house of hope; 32 subjects were recruited from the house of care; and 18 subjects were recruited from the house of females.

\section{Measurements tools}

The demographic characteristics questionnaire consisted of both closed-ended questions and open-ended questions asking about age, gender, level of education, occupation, register process, relapse experience, legal problem status and duration of drug use.

The Drug Taking Confidence Questionnaire is a 50-item questionnaire that assists the clients to measure their self-efficacy by reporting how confident they are in resisting the urge of using drugs in a given situation[24]. The test employs a Likert scale response ranging in 20-point increments. The score was calculated by totaling a respondent's points for each item question. The higher the score indicates the better the self-efficacy. The content validity index was 0.84 and Cronbach's $\alpha$ was 0.98 .

The Stimulant Effect Expectancy Questionnaire (SEEQ) was employed to assess client's perceptions of methamphetamine's effects[25] with adaptation to use in stimulants, such as cocaine including crack and amphetamine[13]. The 46 items of SEEQ comprise the 5 following scales: global positive effects, global negative effects, general arousal, anxiety and relaxation and tension reduction. Each Likert-scale-item scored from 1 to 5 (from disagrees strongly to agree strongly). The higher the mean scores of global positive effect expectancy, general arousal, and relaxation and tension reduction, the higher the client believed in the positive effects of using methamphetamine. The content validity index was 0.84 and Cronbach's $\alpha$ was 0.92 .

The Stage of Change Readiness and Treatment Eagerness Scale is a 19-item questionnaire to assess motivation level of clients that comprise three scales, including recognition, ambivalence, and taking steps[26]. Each item was scored by using a five-point-Likert-scale ranging from strongly disagree to strongly agree. The score was calculated by totaling raw scores from a client's response for each item. The content validity index was 0.93 and Cronbach's $\alpha$ was 0.87 .

The CSI-S is a 32-item checklist to assess how a client handles stressful life circumstances, namely, emotional, behavioral and cognitive abilities that consist of three subscales including eight primary subscales (problem solving, cognitive restructuring, emotional expression, social support, problem avoidance, wishful thinking, self-criticism and social withdrawal), four secondary subscales (problem focused engagement, emotion focused engagement, problem focused disengagement and emotion focused disengagement), and two tertiary subscales (engagement and disengagement)[27]. This study employed a tertiary subscale. The score was calculated by totaling a client's response in a tertiary subscale. High scores on the subscale indicate coping strategies that the client employs. The content validity index was 0.84 and Cronbach's $\alpha$ was 0.91 .

The Positive Affect and Negative Affect Schedule was employed to measure the client's emotional state[28]. It consists of ten items to assess positive affect and another ten items to assess negative affect (NA). A five-point-Likert scale was used, ranging from very slightly or not at all to extremely. The score was calculated by totaling the client's responses for and NA. Higher scores indicate the more positive or NA. The content validity index was 0.90 and Cronbach's $\alpha$ was 0.90 .

The Desire for Speed Questionnaire was designed to measure craving of stimulant drug that consist of 24 items comprising four subscales: expectancy of positive and negative 
JHR

32,4

282

reinforcement, strong desires and intentions to use, mild desires and intentions to use and control[29]. A seven-point-Likert scale was used to measure how strongly they agreed with each statement. The score was calculated by totaling each client's response for every question. The higher the score indicates the stronger the client's craving. The content validity index was 0.88 and Cronbach's $\alpha$ was 0.95 .

The Social Support Questionnaire (SSQ6) is a measurement of global perceptions of perceived available support[30]. The client can mention no more than nine individuals for each list situation. The second part is a client's satisfaction perception score of support that they received in the given situation. Total number of support and satisfaction was obtained by calculating the mean across the number of support and satisfaction ratings. A maximum total for the mean number of support is 9 and 6 for the total satisfaction. The higher the mean score of support number and the total satisfaction indicates the better social support that the client had. The content validity index was 0.93 and Cronbach's $\alpha$ was 0.89 .

Relapse risk as a dependent variable in this study was measured using Stimulant Relapse Risk Scale (SRRS) comprising five subscales: anxiety and intention (AI) to use drug, emotional problem, compulsivity for drug, positive expectancies and lack control over drug and lack of negative expectancy for the drug[7]. The responses were gauged using a three-point-Likert scale. The higher total mean score, the higher risk of relapse during the three to six months following treatment. The content validity index was 0.83 and Cronbach's $\alpha$ was 0.86 .

\section{Data analysis}

Descriptive statistics were used to describe demographic characteristics and risk of relapse of the rehabilitation clients. The level of significance of the study was set at $\alpha=0.05$. Further, Pearson's product moment correlation was used to examine the relationship between self-efficacy, outcome expectancy, motivation, coping, emotional state, craving, social support and relapse risk among clients.

\section{Results}

A total of 165 subjects who met the inclusion criteria were recruited in this study. Two-thirds of the participants were aged between 20 and 29 years. The majority of the participants were male (89 percent). The level of education was mostly senior high school (63.6 percent). More than a half of participants (59.4 percent) were unemployed. In total, 12.7 percent of participants were involved in illegal issues. One-third of the participants had a relative who used methamphetamine. More than half of the participants have been using methamphetamine for one to five years (mean $=6.95, \mathrm{SD}=5.24$ ). A total of 89 participants came to the rehabilitation center because for them it was compulsory (53.9 percent), and the entire participants experienced relapse. In this study it was found that 63 percent of the clients were at a moderate level of methamphetamine relapse risk with a mean score of relapse risk at $56.33(\mathrm{SD}=10.54)$. Among the five factors of relapse risk, AI to use drugs were the highest cause for relapse risk among participants $($ mean $=15.76, \mathrm{SD}=3.36)$, followed by emotional problems $(\mathrm{EP})($ mean $=15.62, \mathrm{SD}=3.71)$, positive expectancies and lack of control over drug use $(\mathrm{PL})$ (mean $=11.29, \mathrm{SD}=3.57$ ), lack of negative expectancies for drug $(\mathrm{NE})($ mean $=7.40, \mathrm{SD}=2.03)$, and at last, compulsivity for drug use (mean $=6.25, \mathrm{SD}=2.21$ ) Table $\mathrm{I}$.

\section{Correlation between selected factors and methamphetamine relapse risk}

There were positive correlations between outcome expectancy, positive emotional state, negative emotional state, craving and relapse risk $(r=0.261, r=0.380, r=0.370, r=0.509$, 


\begin{tabular}{lrrrr}
\hline Variables & Mean & SD & $\begin{array}{r}\text { Methamphetamine } \\
\text { relapse risk }\end{array}$ \\
\hline Self-efficacy & 61.33 & 22.96 & \\
Outcome expectancies & 154.98 & 28.09 & \\
$\quad$ Global positive effects & 37.32 & 8.00 & \\
$\quad$ Global negative effects & 46.55 & 10.82 & \\
$\quad$ General arousal & 30.36 & 6.12 & \\
$\quad$ Anxiety & 28.47 & 3.49 & $\mathbf{2 8 3}$ \\
$\quad$ Relaxation and tension reduction & 12.26 & 4.06 & \\
Motivation & & & \\
$\quad$ Recognition & 29.17 & 2.82 & \\
$\quad$ Ambivalence & 15.35 & 5.20 & \\
$\quad$ Taking steps & 32.06 & 10.27 & \\
Coping & & 10.63 & \\
$\quad$ Engagement coping & 54.18 & 9.59 & \\
$\quad$ Disengagement coping & 54.90 & 9.17 & \\
Emotional state & & 29.65 & Table I. \\
$\quad$ Positive emotional state & 27.73 & 5.21 & Mean and standard \\
$\quad$ Negative emotional state & 27.09 & & independent variables \\
Craving & 60.69 & & \\
Social support & 31.74 & & & \\
$\quad$ Satisfaction of support & & &
\end{tabular}

$p<0.01$, respectively). Self-efficacy had a negative correlation with relapse risk $(r=-0.316$, $p<0.01)$. At last, motivation, social support and coping had no correlation with relapse risk as shown in Table II.

\section{Discussion}

The assessment of relapse risk during treatment is believed to be able to predict relapse following treatment; and that is important for the prevention of relapse[19]. Predictive validity of the SRRS showed that relapse within three months was significantly and positively correlated with AI, PL and NE. Similarly, relapse within six months was significantly and positively correlated with PL and NE. The result of this study showed that AI, EP and PL were the highest cause for relapse among clients. Highest mean score of AI and PL indicates that clients have a tendency to relapse within three months after

\begin{tabular}{lcc}
\hline Variables & Correlation coefficients & $p$-value \\
\hline Self-efficacy & $-0.316^{* *}$ & 0.000 \\
Outcome expectancy & $0.261^{* *}$ & 0.001 \\
Motivation & 0.073 & 0.352 \\
Coping & -0.014 & 0.854 \\
$\quad$ Engagement coping & 0.099 & 0.208 \\
$\quad$ Disengagement coping & $0.380^{* *}$ & 0.000 \\
Emotional state & $0.370^{* *}$ & 0.000 \\
$\quad$ Positive emotional state & $0.509^{* *}$ & 0.000 \\
$\quad$ Negative emotional state & 0.030 & 0.706
\end{tabular}

Table II.

Correlation between selected factors and methamphetamine relapse risk

Note: ***Significant at 0.05 and 0.01 level, respectively (two-tailed) 
JHR

32,4

284

rehabilitation treatment. Even though EP was not significantly correlated with relapse risk, EP showed a significant correlation with the depression scale and other factors of SRSS which indicates that the EP factor has an indirect effect in increasing the subjective desire for drug and thus the relapse risk.

Self-efficacy was negatively correlative with relapse risk $(r=-0.316, p<0.01)$ indicating that the increasing self-efficacy of clients to resist drug use during treatment can decrease relapse risk following treatment. Even though this study showed a moderate correlation between self-efficacy and relapse risk, a prior study found that self-efficacy has the most influence with regard to the risk of relapse[11, 12, 31, 32]. Outcome expectancy was positively correlative with relapse risk $(r=0.261, p<0.01)$ indicating that as the outcome expectancy increased during treatment, relapse risk will increase. The outcome expectancy in this study is defined as an effect that a client expects will occur as a result of drug consumption[14]. Negative emotional state was positively correlative with relapse risk $(r=0.370, p<0.01)$ indicating that as the negative emotional state increases during treatment, relapse risk will increase. It was generally accepted that negative emotional state contributes to a high risk of drug use relapse and the outcome of treatment[16, 33, 34]. Positive emotional state was also positively correlative with relapse risk $(r=0.380, p<0.01)$ indicating that as the positive emotional state increases, relapse risk will increase. Although several studies focused on negative mood as a factor prior to relapse, some studies support that a positive emotional state can also led to relapse following treatment in certain ways[18, 35]. Craving was positively correlative with relapse risk $(r=0.509, p<0.01)$ indicating that as the craving level increases, relapse risk will increase. This finding supported the hypotheses and previous related studies that conclude craving as an intense desire or irresistible urge leads to drug seeking or drug taking that can contribute to relapse[19, 20,36].

In this study, motivation had no correlation to relapse risk because more than half of the participants were compelled to come to the rehabilitation center which indicated that the majority of them were less motivated to take the treatment[37]. Although there was no relationship between overall coping and relapse risk, two subscales of coping including the express emotion and social withdrawal were significantly correlated to relapse risk, indicating a partial support of the study hypothesis. Interestingly, finding from this study is contradictory to those found in the previous studies that social support had correlation with relapse risk[21-23]. The current study used the SSQ6 which is a measurement of global perceptions of perceived available support individual received in the given situation[30], which may be differ from instruments used in other studies. The SSQ6 may not be applicable to measuring received social support from various sources[38] (i.e. friend, neighbor, community leader) among patients who are treating in the closed setting as Substance Rehabilitation Center. Most subjects in this study indicated that the only current supported they had received and satisfied with came from the visit of their family members, which therefore limited an effect of social support on perceived relapse risk.

The implications involving the practice of nursing are that the early detection of methamphetamine relapse risk during treatment by using standardized instruments should be utilized as a part of nursing intervention. Relapse Prevention Therapy should be implemented in the rehabilitation phase for an extended period of time as a continuum program in order to lower relapse risk[39].

\section{Conclusion}

The results showed that in general, clients in the rehabilitation center of NNB in West Java, Indonesia, were at a moderate level of methamphetamine relapse risk. Outcome expectancy, negative emotional state, positive emotional state and craving had positive significant 
correlation with methamphetamine relapse risk. In addition, self-efficacy had a negative Methamphetamine significant correlation with relapse risk. At last, motivation, social support and coping had no correlation with methamphetamine relapse risk.

\section{Limitation of the study and recommendations}

This study employed a set of questionnaires that produce database on client's perception during the rehabilitation phase of treatment. Further, a qualitative research to explore relapse risk during treatment is suggested in order to obtain additional precise data about methamphetamine relapse risk which is relevant to the current situation.

\section{References}

1. United Nations Office on Drugs and Crimes [UNODC]. Indonesia: situation assessment on amphetamine-type stimulants. UNODC; 2013. Available from: www.unodc.org/documents/indonesia/ publication/2013/Indonesia_ATS_2013_low.pdf

2. National Narcotics Board [NNB]. Press release of national narcotics board 2015: public relation division of national narcotics board Indonesia; 2015. Available from: www.bnn.go.id/read/ pressrelease/15191/blog-single.html

3. Robinson TE, Berridge KC. The psychology and neurobiology of addiction: an incentivesensitization view. Addiction. 2000 Aug; 95(S2): S91-117.

4. National Narcotics Board [NNB]. Stages of drug addiction recovery process; 2012. Available from: http://dedihumas.bnn.go.id/read/section/artikel/2012/08/24/514/tahap-tahap-pemulihanpecandu-narkoba

5. Thomson N. Detention as treatment: detention of methamphetamine users in Cambodia, Laos, and Thailand. Open Society Institute; 2010. Available from: www.opensocietyfoundations.org/sites/ default/files/Detention-as-Treatment-20100301.pdf

6. Wilson PH. Relapse prevention: conceptual and methodological issues. In: Wilson PH. editor, Principles and practice of relapse prevention. New York, NY: Guilford Press; 1992. pp. 1-22.

7. Ogai Y, Haraguchi A, Kondo A, Ishibashi Y, Umeno M, Kikumoto H, et al. Development and validation of the stimulant relapse risk scale for drug abusers in Japan. Drug Alcohol Depend. 2007 May; 88(2-3): 174-81. doi: 10.1016/j.drugalcdep.2006.10.005

8. Marlatt GA, Donovan DM. Relapse prevention: maintenance strategies in the treatment of addictive behaviors. New York, NY: Guilford Press; 2005.

9. Witkiewitz K, Marlatt GA. Relapse prevention for alcohol and drug problems: that was Zen, this is Tao. Am Psychol. 2004 May-Jun; 59(4): 224-35. doi: 10.1037/0003-066X.59.4.224

10. Hendershot CS, Witkiewitz K, George WH, Marlatt GA. Relapse prevention for addictive behaviors. Subst Abuse Treat Prev Policy. 2011 Jul; 6(1): 17. doi: 10.1186/1747-597X-6-17

11. Hagman BT. Coping and self-efficacy as predictors of substance use during the first few critical months following substance abuse treatment completion. Wilmington, NC: University of North Carolina; 2004.

12. Kadden RM, Litt MD. The role of self-efficacy in the treatment of substance use disorders. Addict Behav. 2011 Dec; 36(12): 1120-6. doi: 10.1016/j.addbeh.2011.07.032

13. Aarons GA, Brown SA, Stice E, Coe MT. Psychometric evaluation of the marijuana and stimulant effect expectancy questionnaires for adolescents. Addict Behav. 2001 Mar-Apr; 26(2): 219-36.

14. DiClemente CC, Velasquez MM. Motivational interviewing and the stages of change. In: Miller WR, Rollinic S, editors. Motivational interviewing: preparing people for change. New York, NY: The Guilford Press; 2002: pp. 201-16. 
15. Miller WR, Rollnick S. Motivational interviewing: preparing people for change. New York, NY: The Guilford Press; 2002.

16. Hall SM, Havassy BE, Wasserman DA. Effects of commitment to abstinence, positive moods, stress, and coping on relapse to cocaine use. J Consult Clin Psychol. 1991 Aug; 59(4): 526-32.

17. Rohsenow DJ, Monti PM, Martin RA, Michalec E, Abrams DB. Brief coping skills treatment for cocaine abuse: 12-month substance use outcomes. J Consult Clin Psychol. 2000 Jun; 68(3): $515-20$.

18. McKay JR, Rutherford MJ, Alterman AI, Cacciola JS, Kaplan MR. An examination of the cocaine relapse process. Drug Alcohol Depend. 1995 Apr; 38(1): 35-43. doi: 10.1016/0376-8716(95)01098-J

19. Galloway GP, Singleton EG. How long does craving predict use of methamphetamine? Assessment of use one to seven weeks after the assessment of craving: craving and ongoing methamphetamine use. Subst Abuse. 2009 Aug; 1: 63-79.

20. Hartz DT, Frederick-Osborne SL, Galloway GP. Craving predicts use during treatment for methamphetamine dependence: a prospective, repeated-measures, within-subject analysis. Drug Alcohol Depend. 2001 Aug; 63(3): 269-76. doi: 10.1016/S0376-8716(00)00217-9

21. Ellis B, Bernichon T, Yu P, Roberts T, Herrell JM. Effect of social support on substance abuse relapse in a residential treatment setting for women. Eval Program Plann. 2004 May; 27(2): 213-21. doi: 10.1016/j.evalprogplan.2004.01.011

22. Dobkin PL, Civita MD, Paraherakis A, Gill K. The role of functional social support in treatment retention and outcomes among outpatient adult substance abusers. Addiction. 2002; 97(3): 347-56. doi: 10.1046/j.1360-0443.2002.00083.x

23. McMahon RC. Personality, stress, and social support in cocaine relapse prediction. J Subst Abuse Treat. 2001 Sep; 21(2): 77-87. doi: 10.1016/S0740-5472(01)00187-8

24. Annis H, Martin G. Inventory of drug-taking situations. Toronto: Addiction Research Foundation; 1985.

25. Schafer J, Brown SA. Marijuana and cocaine effect expectancies and drug use patterns. J Consult Clin Psychol. 1991 Aug; 59(4): 558-65.

26. Miller WR, Tonigan JS. Assessing drinkers' motivation for change: the Stages of Change Readiness and Treatment Eagerness Scale (SOCRATES). Psycho Addict Behav. 1996; 10(2): 81-9. doi: 10.1037/ 0893-164X.10.2.81

27. Tobin DL, Holroyd KA, Reynolds RV, Wigal JK. The hierarchical factor structure of the coping strategies inventory. Cognit Ther Res. 1989 Aug; 13(4): 343-61. doi: 10.1007/bf01173478

28. Watson D, Clark LA, Tellegen A. Development and validation of brief measures of positive and negative affect: the PANAS scales. J Pers Soc Psychol. 1988 Jun; 54(6): 1063-70.

29. James D, Davies G, Willner P. The development and initial validation of a questionnaire to measure craving for amphetamine. Addiction. 2004 Sep; 99(9): 1181-8. doi: 10.1111/j.1360-0443.2004.00819.x

30. Sarason IG, Sarason BR, Shearin EN, Pierce GR. A brief measure of social support: practical and theoretical implications. J Soc Pers Relat. 1987; 4(4): 497-510.

31. Ibrahim F, Kumar N. Factors effecting drug relapse in Malaysia: an empirical evidence. Asian Soc Sci. 2009; 5(12): 37-44.

32. Ibrahim F, Kumar N, Samah BA. Self efficacy and relapsed addiction tendency: an empirical study. Soc Sci. 2011; 6(4): 277-82.

33. Olsson KL, Cooper RL, Nugent WR, Reid RC. Addressing negative affect in substance use relapse prevention. J Hum Behav Soc Environ. 2016 Jan; 26(1): 2-14. doi: 10.1080/10911359.2015.1058138

34. Serafini K, Malin-Mayor B, Nich C, Hunkele K, Carroll KM. Psychometric properties of the Positive and Negative Affect Schedule (PANAS) in a heterogeneous sample of substance users. Am J Drug Alcohol Abuse. 2016 Mar; 42(2): 203-12. doi: 10.3109/00952990.2015.1133632

35. Larimer ME, Palmer RS, Marlatt GA. Relapse prevention: an overview of Marlatt's cognitive-behavioral model. Alcohol Res Health. 1999; 23(2): 151-60. 
36. Lopez RB, Onyemekwu C, Hart CL, Ochsner KN, Kober H. Boundary conditions of Methamphetamine methamphetamine craving. Exp Clin Psychopharmacol. 2015 Dec; 23(6): 436-44. doi: 10.1037/ pha0000049

37. Ip R, Legosz M, Ellerman Z, Carr A, Seifert N. Mandatory treatment and perceptions of treatment effectiveness Queensland, Australia. Queensland Crime and Misconduct Commission; 2008.

38. Johnsen E, Herringer LG. A note on the utilization of common support activities and relapse following substance abuse treatment. J Psychol. 1993 Jan; 127(1): 73-7. doi: 10.1080/ 00223980.1993.9915544

39. National Instutie on Drug Absue [NIDA]. Principles of drug addiction treatment: a research-based guide. MD: NIH Publication; 2012.

\section{Corresponding author}

Gian Nurmaindah Hendianti can be contacted at: gian.nurmaindah@gmail.com

For instructions on how to order reprints of this article, please visit our website: 